\title{
Agôn
}

Revue des arts de la scène

Critiques | Saison 2012-2013

\section{Le Petit Chaperon Rouge de Joël Pommerat}

Un conte renouvelé

\section{Caroline Châtelet}

\section{Q OpenEdition}

Journals

Édition électronique

URL : http://journals.openedition.org/agon/2602

DOI : 10.4000/agon.2602

ISSN : 1961-8581

Éditeur

Association Agôn

Référence électronique

Caroline Châtelet, "Le Petit Chaperon Rouge de Joël Pommerat », Agôn [En ligne], Critiques, mis en ligne le 13 mai 2013, consulté le 23 septembre 2020. URL : http://journals.openedition.org/agon/2602 ; DOI : https://doi.org/10.4000/agon.2602

Ce document a été généré automatiquement le 23 septembre 2020

Association Agôn et les auteurs des articles 


\title{
Le Petit Chaperon Rouge de Joël Pommerat
}

\author{
Un conte renouvelé
}

Caroline Châtelet

\section{RÉFÉRENCE}

Le Petit Chaperon Rouge de Joël Pommerat, d'après le conte populaire. Assistant à la mise en scène Philippe Carbonneaux. Avec Rodolphe Martin, Murielle Martinelli, Isabelle Rivoal. Scénographie et costumes Marguerite Bordat, scénographie et lumières Eric Soyer, suivi de la réalisation scénographique Thomas Ramon, aide à la documentation Evelyne Pommerat, recherche son Grégoire Leymarie, François Leymarie, régie son Grégoire Chomel, régie lumière Cyril Cotte, direction technique Emmanuel Abate. Production Compagnie Louis Brouillard, coproduction Centre Dramatique Régional de Tours, Théâtre Brétigny Scène conventionnée du Val d'Orge, avec le soutien de la Région Haute-Normandie. Maison des Métallos - du 17 avril au 5 mai 2013. http:// www.maisondesmetallos.org

1 Pourquoi aller au théâtre? Cette question, qui recoupe un faisceau de motivations intellectuelles, de divertissement, sociales - en emporte avec elle une autre : pourquoi y retourner? Si les réponses possibles sont complexes et intimes, il est certains spectacles, rares, devant lesquels ces interrogations résonnent particulièrement. C'est le cas du Petit Chaperon rouge de Joël Pommerat, spectacle qui en donnant un caractère acceptable à certaines difficiles étapes de la vie, en aidant à grandir, en somme, n'oblitère pas le plaisir de la répétition inlassable du conte. Avec cette création, le fondateur de la compagnie Louis Brouillard procède à une réécriture, permettant une focalisation sur les rapports entre le Chaperon, sa mère et sa Grand-mère. Il est question ici d'amour filial et maternel, ainsi que de transmission, d'initiation et de tout ce que le fait de grandir emporte - acquisition de l'autonomie, de la confiance en soi et de l'autre, indépendance. Dans ce théâtre au dispositif minimal, essentiel, trois 
comédiens interprètent cinq personnages. Tandis que le conteur, présent dès le début sur le côté de l'avant-scène - position de figure omnisciente qui nous fera traverser le conte -, endosse également le rôle du loup, les deux comédiennes se partagent ceux de la grand-mère, de la mère et du Chaperon dans un savant jeu de passe-passe générationnel. Pas de père dans cette lecture-là, mais une mère bien occupée n'ayant que peu de temps pour jouer en imitant un monstre terrifiant. C'est donc autant pour échapper à l'ennui, pour prouver son autonomie, que, peut-être, pour se frotter " pour de vrai » à la figure du monstre que l'enfant demande à aller voir, seule, la grand-mère. Si la fin du conte développe sa propre version, la péripétie est semblable au canevas habituel : rencontrant en chemin le loup, celui-ci dévorera aïeule et enfant. Mais Joël Pommerat n'énonce pas de sanctions définitives et irrémédiables. Révolue, l'époque de Charles Perrault et l'appel à la moralité des jeunes filles. Après le sauvetage des deux femmes, l'histoire se prolonge pour se clore sur le cycle de la vie: devenue grande, le Chaperon (cette fois interprétée par la comédienne jouant précédemment la mère) rend visite à sa vieille mère (jouée, elle, par le Chaperon). Une alternance salvatrice, qui fait de la transgression des interdits un acte constitutif de l'existence. Cette vision pertinente, Joël Pommerat la met en scène sans gommer la force du récit. C'est donc bien un conte qui nous est narré, comme ne cesse de le rappeler le narrateur, avec tout ce que cette fable suppose d'alternance d'angoisse, d'émotion et de rire. Maîtrisant tous les artifices théâtraux, Joël Pommerat investit un dispositif scénographique simple, et tel un prestidigitateur, fait surgir de celui-ci personnages, atmosphères, lieux. C'est par l'entremise du narrateur que les personnages stylisés acquièrent leur épaisseur et que les frayeurs intimes, attirances enfantines et ancestrales pour les figures du monstre, se déploient. Rien n'est de trop et quoique virtuose, la mise en scène, fondée sur une économie de moyens, soutient avec subtilité et puissance le récit. Mais ce que produit aussi ce Chaperon, c'est une jouissance à voir et revoir une histoire qui en travaillant les peurs archaïques les apaise, les rendant acceptables et maîtrisables. Plaisir du conte et de la répétition d'une parole toujours vivante...

Devant ce spectacle et l'intérêt sans cesse renouvelé de sa découverte me revient en mémoire cette phrase de Sarah Kane : « le théâtre n'a pas de mémoire, ce qui fait de lui le plus existentiel de tous les arts. C'est sans doute pour ça que je ne cesse d'y retourner, dans l'espoir que, dans une salle obscure, quelqu'un me montrera une image qui pénétrera dans mon esprit en s'embrasant, y laissant une marque plus permanente que ce moment lui-même.» 